Article

\title{
Determination of the Real Loss of Power for a Condensing and a Backpressure Turbine by Means of Second Law Analysis
}

\author{
Henrik Holmberg*, Pekka Ruohonen and Pekka Ahtila \\ Helsinki University of Technology, Department of Energy Technology, P.O.box 4400, Fin-02015 TKK, \\ Finland; E-Mails: pekka.ruohonen@tkk.fi (P.R.); pekka.ahtila@tkk.fi (P.A.)
}

* Author to whom correspondence should be addressed; E-Mail: henrik.holmberg@ $@$ tkk.fi; Tel.: +358-9-451-5746; Fax: +358-9-451-3674.

Received: 19 August 2009 / Accepted: 27 October 2009 / Published: 30 October 2009

\begin{abstract}
All real processes generate entropy and the power/exergy loss is usually determined by means of the Gouy-Stodola law. If the system only exchanges heat at the environmental temperature, the Gouy-Stodola law gives the correct loss of power. However, most industrial processes exchange heat at higher or lower temperatures than the actual environmental temperature. When calculating the real loss of power in these cases, the Gouy-Stodola law does not give the correct loss if the actual environmental temperature is used. The first aim of this paper is to show through simple steam turbine examples that the previous statement is true. The second aim of the paper is to define the effective temperature to calculate the real power loss of the system with the Gouy-Stodola law, and to apply it to turbine examples. Example calculations also show that the correct power loss can be defined if the effective temperature is used instead of the real environmental temperature.
\end{abstract}

Keywords: Gouy-Stodola law; entropy generation rate; exergy; effective temperature

\section{Introduction}

Exergy is usually defined as the maximum work output attainable in the natural environment, or the minimum work input necessary to realize the reverse process [1]. All real processes generate entropy, and loss of exergy is determined by means of the Gouy-Stodola law: 


$$
\mathrm{E}_{\text {loss }}=\mathrm{T}_{\mathrm{o}} \delta
$$

where $T_{0}$ is the real environmental temperature outside the system boundaries and $\delta$ the entropy generation rate. Equation (1) also expresses the improvement potential of the system.

If the system only exchanges heat at the real environmental temperature $T_{0}$, Equation (1) gives the exact improvement potential of the system. However, most industrial processes emit or absorb heat at a temperature level other than the real environmental temperature. It is easy to show that in these cases, Equation (1) does not give the real improvement potential of the system if the real environmental temperature $\mathrm{T}_{\mathrm{o}}$ is used.

The first aim of this paper is to show through simple steam turbine example cases that the previous statement is true. The second aim of the paper is to define a so-called effective temperature $\mathrm{T}_{\text {eff }}$ to calculate the real power loss of the system in all cases from Equation (1). From now on, the loss term in Equation (1) is always called power loss $\left(\mathrm{P}_{\text {loss }}\right)$ to distinguish it from exergy loss $\left(\mathrm{E}_{\text {loss }}\right)$, which is usually calculated using the real environmental temperature.

One of the simplest processes in which entropy generation occurs is steam or gas expansion in a turbine. Calculation of the power loss in a turbine using the Gouy-Stodola law has been studied in [1-7]. With the exception of Bejan [7], all of the authors have used the real environmental temperature $\mathrm{T}_{\mathrm{o}}$ to calculate the power loss. Bejan states that the temperature in Equation (1) falls somewhere between $\mathrm{T}_{\text {out,rev }}$ and $\mathrm{T}_{\text {out,real }}$ when the power loss is calculated in steam expansion. However, Bejan does not state what the exact temperature in Equation (1) should then be. Lampinen and Wiksten have presented in Reference [8] an in-depth analysis of the determination of the correct temperature in Equation (1) to calculate the real power loss.

In this paper, we will apply the ideas of Lampinen and Wiksten to calculate the real power loss from Equation (1) for the following example systems; i) steam expansion in a turbine, ii) steam expansion in a condensing turbine + condenser, and iii) steam expansion in a backpressure turbine + heat exchanger. The condensing turbine + condenser represents a condensing power plant in which the main goal is to maximize power generation. The backpressure turbine + heat exchanger represents an industrial CHP plant (combined heat and power plant) in which the primary goal is usually to produce heat, with electricity being obtained as a by-product. The paper also discusses the contradiction which arises when the real environmental temperature $\mathrm{T}_{\mathrm{o}}$ is applied to industrial processes in the exergy analysis.

\section{Calculation of the Loss of Power}

\subsection{General theory}

According to the theory presented by Lampinen and Wiksten, the correlation between the maximum power production, real power production and the Gouy-Stodola law is defined as follows [8]:

$$
\mathrm{P}_{\max }-\mathrm{P}=\mathrm{T}_{\mathrm{eff}} \delta
$$

where $\mathrm{P}_{\max }$ is the maximum power production, $\mathrm{P}$ the real power production, $\mathrm{T}_{\text {eff }}$ the effective temperature and $\delta$ the entropy generation rate. Instead of the real environmental temperature $T_{o}$, the so-called effective temperature $T_{\text {eff }}$ is used in Equation (2). Next, we will define the effective temperature in Equation (2). 
If mechanical energy terms are ignored, the energy balance for a stationary flow becomes:

$$
\mathrm{P}=\dot{\mathrm{m}}\left(\mathrm{h}_{1}-\mathrm{h}_{2}\right)+\mathrm{Q}
$$

where $\mathrm{P}$ is the mechanical power, $\mathrm{h}_{1}$ the specific enthalpy of the flow at the inlet, $\mathrm{h}_{2}$ the specific enthalpy of the flow at the outlet, and Q the net heat input to the system. In Equation (3) the work done by the system and the heat flow into the system have a positive sign.

The Second Law of Thermodynamics can be written as follows [8]:

$$
\dot{\mathrm{m}}\left(\mathrm{s}_{2}-\mathrm{s}_{1}\right)-\int_{1}^{2} \frac{\mathrm{dQ}}{\mathrm{T}}=\delta
$$

where $s_{1}$ is the specific entropy at the inlet, $s_{2}$ the specific entropy at the outlet, and $\delta$ the entropy generation rate. The temperature $\mathrm{T}$ in the integral represents the temperature of the boundary over which the heat dQ flows to or from the system.

It is obvious that the best-known process is a reversible process. By neglecting mechanical energy terms, the energy balance and the entropy equation for a reversible process may be written as follows:

$$
\begin{gathered}
\mathrm{P}_{\text {max }}=\dot{\mathrm{m}}\left(\mathrm{h}_{1}-\mathrm{h}_{2 \mathrm{R}}\right)+\mathrm{Q} \\
\dot{\mathrm{m}}\left(\mathrm{s}_{2 \mathrm{R}}-\mathrm{s}_{1}\right)=\int_{1}^{2} \frac{\mathrm{dQ}}{\mathrm{T}}
\end{gathered}
$$

where $h_{2 R}$ and $s_{2 R}$ represent states of the enthalpy and entropy after a reversible process, respectively. Term Q represents the net heat input to the system. The sign of Q is negative if the system emits more heat into the environment than it absorbs. In Equation (5b), the heat integral is defined by applying the definition presented by Lampinen and Wiksten in [8]. The heat integral is defined as follows:

$$
\frac{\mathrm{Q}}{\mathrm{T}_{\mathrm{eff}}}=\int_{1}^{2} \frac{\mathrm{dQ}}{\mathrm{T}}
$$

where $T_{\text {eff }}$ represents the effective temperature. Substituting Equation (6) first in Equations (4) and (5b), and then Equation (4) in Equation (3) and Equation (5b) in Equation (5a), the power loss $\mathrm{P}_{\max }-\mathrm{P}$ becomes:

$$
\mathrm{P}_{\max }-\mathrm{P}=\dot{\mathrm{m}}\left[\left(\mathrm{h}_{2}-\mathrm{h}_{2 \mathrm{R}}\right)-\mathrm{T}_{\text {eff }}\left(\mathrm{s}_{2}-\mathrm{s}_{2 \mathrm{R}}\right)\right]+\mathrm{T}_{\text {eff }} \delta
$$

The correlation between the entropy generation rate and the loss of power is expressed using Equation (2), and on the basis of this definition the effective temperature from Equation (7) becomes:

$$
\mathrm{T}_{\text {eff }}=\frac{\left(\mathrm{h}_{2}-\mathrm{h}_{2 \mathrm{R}}\right)}{\left(\mathrm{s}_{2}-\mathrm{s}_{2 \mathrm{R}}\right)}
$$

If the specific heat capacity and pressure remain constant, the change of enthalpy and entropy depends only on the temperature, and Equation (11) can be written as follows:

$$
\mathrm{T}_{\text {eff }}=\frac{\left(\mathrm{T}_{2}-\mathrm{T}_{2 \mathrm{R}}\right)}{\ln \frac{\mathrm{T}_{2}}{\mathrm{~T}_{2 \mathrm{R}}}}
$$


where $T_{2 R}$ is the theoretical outlet temperature after a reversible process and $T_{2}$ the real outlet temperature.

\subsection{Calculation of power loss for steam turbine systems}

Figure 1 shows three turbine systems for which the power loss will be calculated. The turbine systems in Figure 1 are stationary and can be treated as adiabatic, in which case the entropy generation rate becomes:

$$
\delta=\sum_{\mathrm{i}=1}^{\mathrm{n}} \dot{\mathrm{m}}_{\mathrm{i}} \mathrm{s}_{\mathrm{i}, \text { out }}-\sum_{\mathrm{j}=1}^{\mathrm{m}} \dot{\mathrm{m}}_{\mathrm{j}} \mathrm{s}_{\mathrm{j}, \text { in }}
$$

where $\dot{m}$ is the mass flow and $\mathrm{s}$ the specific entropy of the flow. For steam flows the entropy values are taken from the steam table.

Figure 1. Calculation of losses of power for three different steam turbine systems.

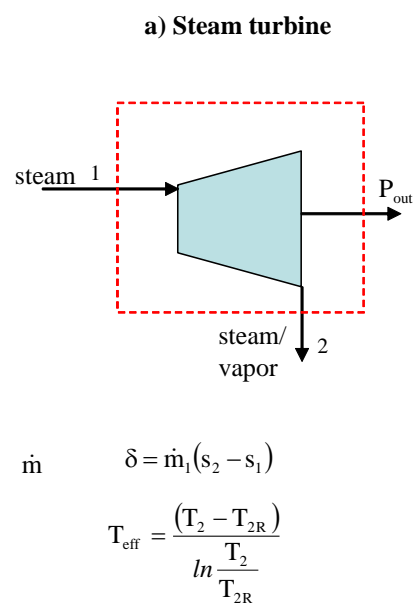

$T_{2 R}$ is the steam temperature after isentropic expansion $\left(s_{1}=s_{2 R}\right)$

\begin{tabular}{|l|}
\hline Symbols: \\
$\delta$ entropy generation rate $(\mathrm{W} / \mathrm{K})$ \\
T temperature $(\mathrm{K})$ \\
s specific entropy $(\mathrm{J} / \mathrm{kgK})$ \\
$\dot{m}$ mass flow $(\mathrm{kg} / \mathrm{s})$ \\
Subscripts: \\
eff effective, \\
R reversible \\
\hline
\end{tabular}

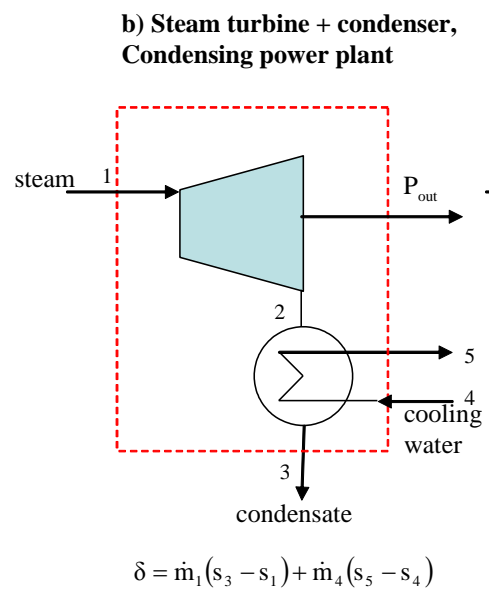

In this case, the outlet temperature of the cooling water $\left(\mathrm{T}_{5}\right)$ must have a value which gives the value zero for the entropy generation rate. When the average heat capacity is used for cooling water the entropy generation rate can be re-written as follows:

$$
\begin{aligned}
& \delta=\dot{\mathrm{m}}_{1}\left(\mathrm{~s}_{3}-\mathrm{s}_{1}\right)+\dot{\mathrm{m}}_{4} \mathrm{c}_{\mathrm{p}, \mathrm{w}} \ln \frac{\mathrm{T}_{5}}{\mathrm{~T}_{4}} \\
& \text { By setting } \delta=0 \\
& \Rightarrow \mathrm{T}_{5 \mathrm{R}}=\mathrm{T}_{4} \exp \left(\frac{\dot{\mathrm{m}}_{1}\left(\mathrm{~s}_{1}-\mathrm{s}_{3}\right)}{\dot{\mathrm{m}}_{4} \mathrm{c}_{\mathrm{p}, \mathrm{w}}}\right) \\
& \Rightarrow \mathrm{T}_{\text {eff }}=\frac{\left(\mathrm{T}_{5}-\mathrm{T}_{5 \mathrm{R}}\right)}{\ln \frac{\mathrm{T}_{5}}{\mathrm{~T}_{5 \mathrm{R}}}}
\end{aligned}
$$

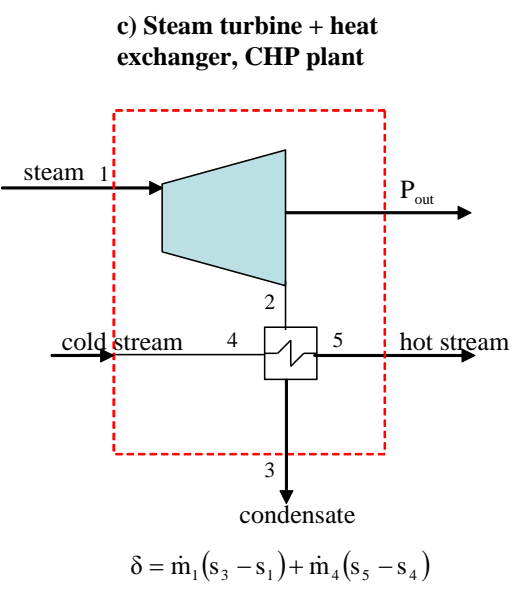

In this case, the outlet temperature of the condensate $\left(\mathrm{T}_{3}\right)$ must have a value which gives the value zero for the entropy generation rate. The temperature $\left(\mathrm{T}_{3 \mathrm{R}}\right)$ is obtained from the steam tables.

$\Rightarrow \quad \mathrm{T}_{\text {eff }}=\frac{\left(\mathrm{T}_{3}-\mathrm{T}_{3 \mathrm{R}}\right)}{\ln \frac{\mathrm{T}_{3}}{\mathrm{~T}_{3 \mathrm{R}}}}$

The total differential of the entropy is:

$$
d s=c_{p} \frac{d T}{T}-\left(\frac{\partial v}{\partial T}\right)_{p} d p
$$


where $c_{p}$ is the specific heat capacity, $T$ the temperature, $v$ the specific volume and $p$ the pressure. In the case of cooling water, the pressure remains the same $(\mathrm{dp}=0)$ and the change of entropy can be calculated from Equation (11) by integration:

$$
\mathrm{s}_{2}-\mathrm{s}_{1}=\mathrm{c}_{\mathrm{p}} \ln \frac{\mathrm{T}_{2}}{\mathrm{~T}_{1}}
$$

where $T_{2}$ is the temperature of the final state and $T_{1}$ the temperature of the initial state.

Figure 1 also shows how to define the entropy generation rate and the effective temperature for each system. In the case of the steam turbine, temperatures $T_{2}$ and $T_{2 R}$ may be the same if the steam is a mixture of saturated vapor and water after the expansion. Applying the l'Hospital's rule, the effective temperature becomes [9]:

$$
\mathrm{T}_{\mathrm{eff}}=\lim _{\mathrm{T}_{2->\mathrm{T}_{2} \mathrm{R}}} \frac{\left(\mathrm{T}_{2}-\mathrm{T}_{2 \mathrm{R}}\right)}{\ln \frac{\mathrm{T}_{2}}{\mathrm{~T}_{2 \mathrm{R}}}}=\frac{1}{\frac{1}{\mathrm{~T}_{2 \mathrm{R}}}}=\mathrm{T}_{2 \mathrm{R}}
$$

\section{Results and Discussion}

Figure 2 shows an example of the calculation of the power loss for steam expansion in a condensing and a backpressure turbine. It is obvious that the power loss for steam expansion in a turbine must be the enthalpy difference $\mathrm{h}_{2}-\mathrm{h}_{2 \mathrm{R}}$, which is $59.45 \mathrm{~kJ} / \mathrm{kg}$ and $87.94 \mathrm{~kJ} / \mathrm{kg}$ for the condensing and the backpressure turbine in the example case, respectively.

Figure 2. Example of the calculation of the power loss for steam expansion in a condensing and a backpressure turbine.

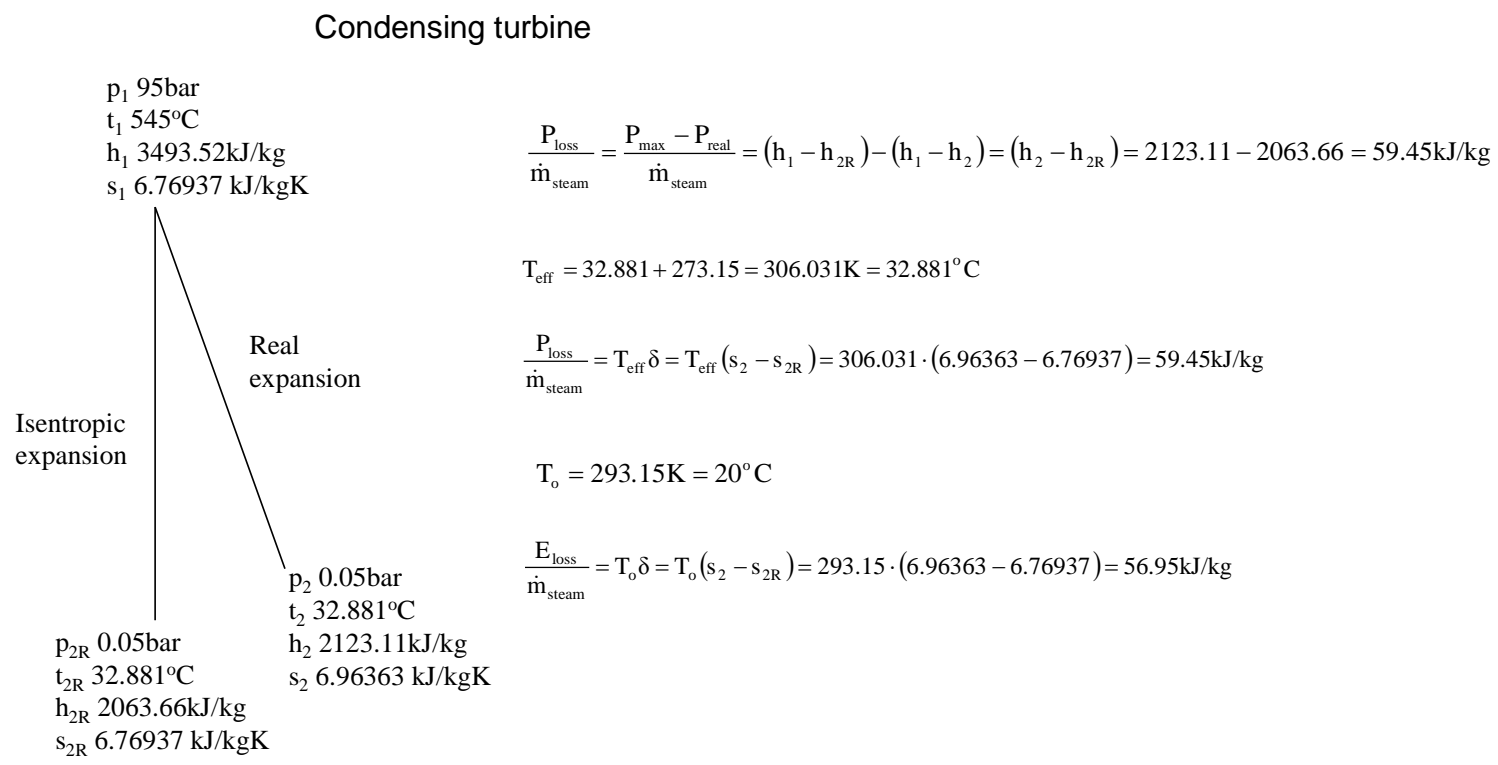


Figure 2. Cont.

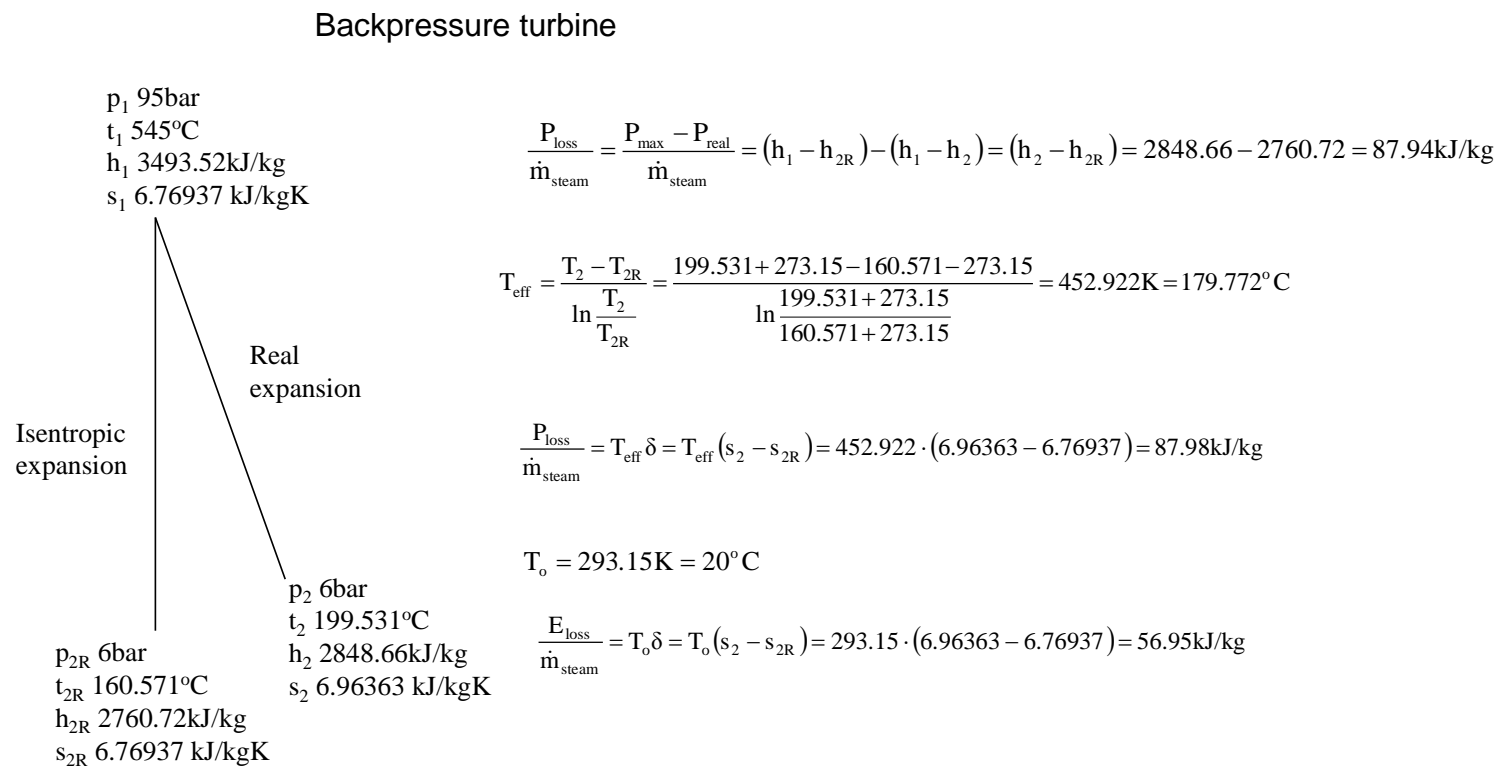

If a real environmental temperature of $20{ }^{\circ} \mathrm{C}$ is used, the power/exergy loss (see definitions in the Introduction) always becomes $56.95 \mathrm{~kJ} / \mathrm{kg}$, which is not the same as the difference $\mathrm{h}_{2}-\mathrm{h}_{2 \mathrm{R}}$. However, the turbine example shows that the Gouy-Stodola law gives the correct power loss when the entropy generation rate is multiplied by the effective temperature defined using Equation (3). This simple example already reveals that it is not always correct to use the real environmental temperature with the Gouy-Stodola law. The example calculations in Figure 3 show in more detail when it is correct to use the Gouy-Stodola law for steam turbine calculations. Figure 3 shows two steam turbine + condenser systems. In real expansion, the turbine and the condenser generate entropy. In isentropic expansion, only the condenser generates entropy, but steam expansion in the turbine is isentropic. The most important observation in Figure 3 is that the sum of $\mathrm{P}_{\text {out }}+\mathrm{P}_{\text {loss }}$ (real power production + power loss) becomes the same for both expansion cases when effective temperatures are used. The sum of $\mathrm{P}_{\text {out }}+\mathrm{P}_{\text {loss }}$ gives the maximum power production of the system when no entropy generation occurs (i.e., a reversible system). As Figure 3 shows, the entropy generation rate reduces in isentropic expansion, which leads to lower power loss (improvement potential of the system) and greater power production. In the case of isentropic expansion, the power loss can only be reduced in a heat exchanger and the improvement potential is $615 \mathrm{~kW}$.

On the basis of Figure 3, it is obvious that the $P_{\text {loss }}$ reveals the real improvement potential of the system, and the sum of $\mathrm{P}_{\text {out }}+\mathrm{P}_{\text {loss }}$ must always be the same for the system. However, this is not valid if the real environmental temperature $\left(20^{\circ} \mathrm{C}\right.$ in Figure 3$)$ is used instead of the effective temperature. For real expansion the sum of $\mathrm{P}_{\text {out }}+\mathrm{P}_{\text {loss }}$ would be $14,863 \mathrm{~kW}(12,583 \mathrm{~kW}+293.15 \mathrm{~K} \times 7,777 \mathrm{~kW} / \mathrm{K})$, if the real environmental temperature was used. For isentropic expansion the corresponding sum would be $13,185 \mathrm{~kW}(12,583 \mathrm{~kW}+293.15 \mathrm{~K} \times 2.055 \mathrm{~kW} / \mathrm{K})$. 
Figure 3. Example of the calculation of the power loss for a steam turbine + condenser system.

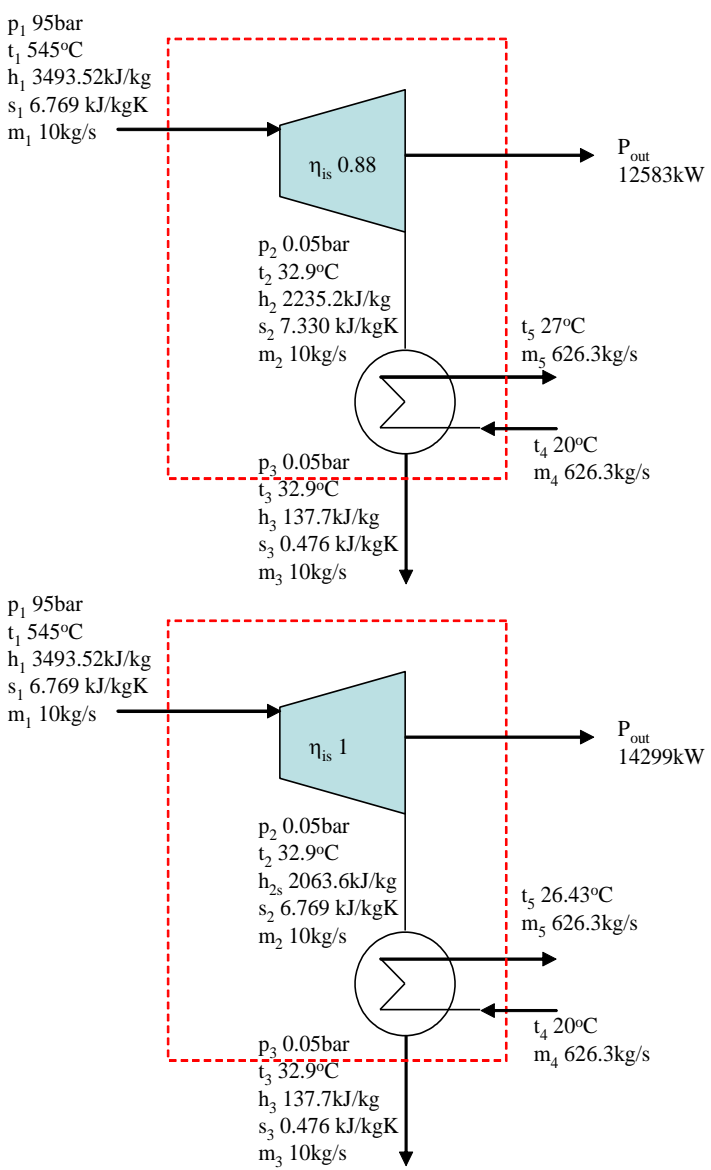

$$
\begin{aligned}
& \text { Real expansion } \\
& \delta=\dot{\mathrm{m}}_{1}\left(\mathrm{~s}_{3}-\mathrm{s}_{1}\right)+\dot{\mathrm{m}}_{4} \mathrm{c}_{\mathrm{p}} \ln \frac{\mathrm{t}_{5}+273.15}{\mathrm{t}_{4}+273.15}=7.777 \frac{\mathrm{kW}}{\mathrm{K}} \\
& \mathrm{t}_{5 \mathrm{R}}=\left(\mathrm{t}_{4}+273.15\right) \exp \left(\frac{\dot{\mathrm{m}}_{1}\left(\mathrm{~s}_{1}-\mathrm{s}_{3}\right)}{\dot{\mathrm{m}}_{4} \mathrm{c}_{\mathrm{pv}}}\right)-273.15=26.22^{\circ} \mathrm{C} \\
& \mathrm{T}_{\text {eff }}=\frac{\mathrm{t}_{5}-\mathrm{t}_{5 \mathrm{R}}}{\ln \left(\frac{\mathrm{t}_{5}+273.15}{\mathrm{t}_{5 \mathrm{R}}+273.15}\right)}=299.761 \mathrm{~K} \\
& \mathrm{P}_{\text {loss }}=\mathrm{T}_{\text {eff }} \delta=2331 \mathrm{~kW} \\
& \mathrm{P}_{\text {max }}=\mathrm{P}_{\text {out }}+\mathrm{P}_{\text {loss }}=14914 \mathrm{~kW} \\
& \text { Isentropic expansion } \\
& \delta=\dot{\mathrm{m}}_{1}\left(\mathrm{~s}_{3}-\mathrm{s}_{1}\right)+\dot{\mathrm{m}}_{4} \mathrm{c}_{\mathrm{p}} \ln \frac{\mathrm{t}_{5}+273.15}{\mathrm{t}_{4}+273.15}=2.055 \frac{\mathrm{kW}}{\mathrm{K}} \\
& \mathrm{t}_{5 \mathrm{R}}=\left(\mathrm{t}_{4}+273.15\right) \exp \left(\frac{\dot{\mathrm{m}}_{1}\left(\mathrm{~s}_{1}-\mathrm{s}_{3}\right)}{\dot{\mathrm{m}}_{4} \mathrm{c}_{\mathrm{pv}}}\right)-273.15=26.22^{\circ} \mathrm{C} \\
& \mathrm{P}_{\text {loss }}=\mathrm{T}_{\text {eff }} \delta=615 \mathrm{~kW} \\
& \mathrm{~T}_{\text {eff }}=\frac{\mathrm{P}_{\text {out }}+\mathrm{P}_{\text {loss }}=14914 \mathrm{~kW}}{\ln \left(\frac{\mathrm{t}_{5}+273.15}{\mathrm{t}_{5 \mathrm{R}}+273.15}\right)}=299.47 \mathrm{~K}
\end{aligned}
$$

a) If the system only changes heat at the environmental temperature $t_{0}\left(=20^{\circ} \mathrm{C}\right)$ and steam expansion is isentropic, no entropy generation occurs and the $\mathrm{P}_{\max }$ becomes:

$\mathrm{P}_{\max }=\mathrm{P}_{\text {out }}=\dot{\mathrm{m}}_{1}\left[\mathrm{~h}_{1}\left(95 \mathrm{bar}, 545^{\circ} \mathrm{C}\right)-\mathrm{h}_{2 \mathrm{~s}}\left(0.02338 \mathrm{bar}, 20^{\circ} \mathrm{C}\right)\right]=10 \cdot(3493.52-1981.41)=15121 \mathrm{~kW}$

The same result is also obtained using the traditional exergy equation:

$\mathrm{P}_{\max }=\dot{\mathrm{m}}_{1}\left(\mathrm{e}_{1}-\mathrm{e}_{3}\right)=\dot{\mathrm{m}}_{1}\left[\mathrm{~h}_{1}-\mathrm{h}_{3}^{\prime}-\mathrm{T}_{\mathrm{o}}\left(\mathrm{s}_{1}-\mathrm{s}_{3}^{\prime}\right)\right]=10 \cdot[3493.52-83.81-293.15 \cdot(6.76937-0.26912)]=15121 \mathrm{~kW}$

where $\mathrm{s}_{3}$ ' and $\mathrm{h}_{3}$ ' are values of the saturated condensate at the temperature of $20^{\circ} \mathrm{C}$ and pressure of $0.02338 \mathrm{bar}$.

b) If the system only exchanges heat at the environmental temperature $t_{0}\left(=20^{\circ} \mathrm{C}\right)$ but the turbine generates entropy $\left(\eta_{\text {is }}=0.88\right)$ then $P_{\text {out }}$, entropy generation rate $\delta$ and $\mathrm{P}_{\max }$ become:

$\mathrm{P}_{\text {out }}=\dot{\mathrm{m}}_{1}\left[\mathrm{~h}_{1}\left(95 \mathrm{bar}, 545^{\circ} \mathrm{C}\right)-\mathrm{h}_{2}\left(0.02338 \mathrm{bar}, 20^{\circ} \mathrm{C}\right)\right]=10 \cdot(3493.52-2162.86)=13306.6 \mathrm{~kW}$

$\delta=\dot{\mathrm{m}}_{1}\left(\mathrm{~s}_{2}-\mathrm{s}_{1}\right)=10 \cdot(7.388-6.768)=6.19 \mathrm{~kW} / \mathrm{K} \quad \mathrm{T}_{\text {eff }}=\mathrm{T}_{\mathrm{o}}=293.15 \mathrm{~K} \quad \mathrm{P}_{\max }=\mathrm{P}_{\text {out }}+\mathrm{T}_{0} \delta=13306.6+293.15 \cdot 6.19=15121 \mathrm{~kW}$

In theory, the maximum power production would be achieved if the system only exchanged heat at the environmental temperature and the process was reversible. It is obvious that this is not possible, but the theoretical maximum power production can be defined using the classic exergy equation, as the example calculation in Figure 3 shows (point a below turbines). The example calculation (point $\mathrm{b}$ below turbines) in Figure 3 also shows that it is correct to use the real environmental temperature with the Gouy-Stodola law if the system only exchanges heat with the environment at this temperature (i.e., $\left.\mathrm{P}_{\max }=\mathrm{P}_{\text {out }}+\mathrm{P}_{\text {loss }}\right)$. Because several processes may exchange heat at much higher or lower temperatures than the real environmental temperature, the use of the environmental temperature with the Gouy-Stodola law may cause a significant error in the determination of the power loss. In the cases of this study, the error already becomes considerable for a CHP plant (see steam expansion for a 
backpressure turbine in Figure 2). Figure 4 shows the calculation of the power loss for a backpressure turbine/CHP plant. Example calculations show that the sum of $\mathrm{P}_{\text {out }}+\mathrm{P}_{\text {loss }}$ is not the same if the isentropic efficiency of the turbine changes ( 0.88 and 1 in Figure 4$)$. The result is different compared with the condensing turbine, where the isentropic efficiency has no influence on the sum of $\mathrm{P}_{\text {out }}+\mathrm{P}_{\text {loss. }}$.

Figure 4. Example of the calculation of the power loss for a backpressure steam turbine + heat exchanger system.

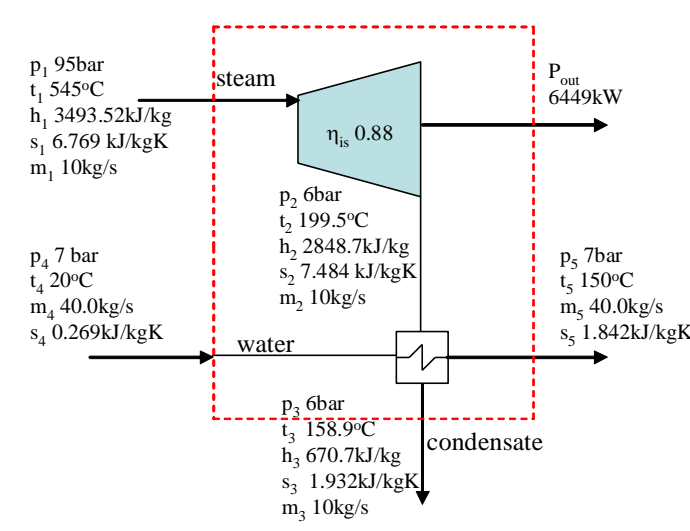

$$
\begin{aligned}
& \text { Real expansion } \\
& \delta=\dot{\mathrm{m}}_{1}\left(\mathrm{~s}_{3}-\mathrm{s}_{1}\right)+\dot{\mathrm{m}}_{4}\left(\mathrm{~s}_{5}-\mathrm{s}_{4}\right)=13.48 \mathrm{~kJ} / \mathrm{K} \\
& \mathrm{s}_{3 \mathrm{R}}=0.583 \mathrm{~kJ} / \mathrm{kgK} \quad \mathrm{t}_{3 \mathrm{R}}=40.86^{\circ} \mathrm{C} \\
& \mathrm{T}_{\text {eff }}=\frac{\mathrm{t}_{3}-\mathrm{t}_{3 \mathrm{R}}}{\ln \left(\frac{\mathrm{t}_{3}+273.15}{\mathrm{t}_{3 \mathrm{R}}+273.15}\right)}=369.88 \mathrm{~K} \\
& \mathrm{P}_{\text {loss }}=\mathrm{T}_{\text {eff }} \delta=4986 \mathrm{~kW} \\
& \mathrm{P}_{\max }=\mathrm{P}_{\text {out }}+\mathrm{P}_{\text {loss }}=11435 \mathrm{~kW}
\end{aligned}
$$

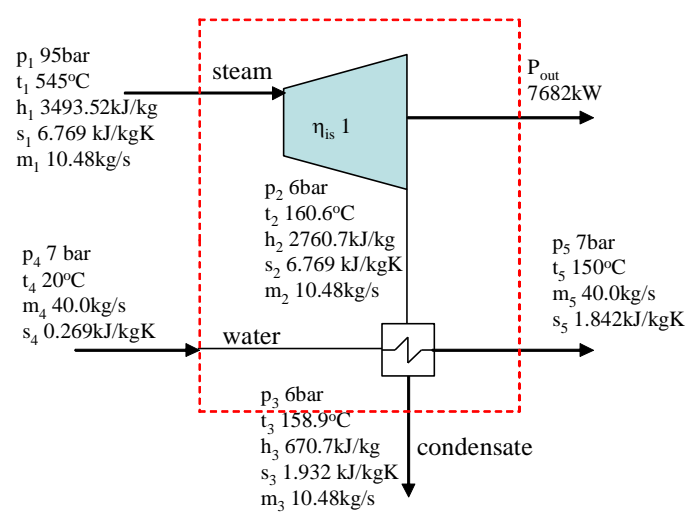

Isentropic expansion

$\delta=\dot{\mathrm{m}}_{1}\left(\mathrm{~s}_{3}-\mathrm{s}_{1}\right)+\dot{\mathrm{m}}_{4}\left(\mathrm{~s}_{5}-\mathrm{s}_{4}\right)=11.15 \mathrm{~kJ} / \mathrm{K}$

$\mathrm{s}_{3 \mathrm{R}}=0.868 \mathrm{~kJ} / \mathrm{kgK} \quad \mathrm{t}_{3 \mathrm{R}}=63^{\circ} \mathrm{C}$

$\mathrm{T}_{\text {eff }}=\frac{\mathrm{t}_{3}-\mathrm{t}_{3 \mathrm{R}}}{\ln \left(\frac{\mathrm{t}_{3}+273.15}{\mathrm{t}_{3 \mathrm{R}}+273.15}\right)}=382.1 \mathrm{~K}$

$\mathrm{P}_{\text {loss }}=\mathrm{T}_{\text {eff }} \delta=4258 \mathrm{~kW}$

$\mathrm{P}_{\max }=\mathrm{P}_{\text {out }}+\mathrm{P}_{\text {loss }}=11940 \mathrm{~kW}$

However, the results in Figure 4 behave consistently. In the case of a backpressure turbine/CHP plant, the water flow must be heated from $20{ }^{\circ} \mathrm{C}$ to $150{ }^{\circ} \mathrm{C}$. If the isentropic efficiency improves and the steam still expands to a pressure of 6 bar, the turbine produces more power. Due to increased power production the heat content of the outlet steam is not great enough to heat the entire water flow to the desired final temperature. To heat the entire water flow to a temperature of the $150{ }^{\circ} \mathrm{C}$ the steam mass flow $\mathrm{m}_{1}$ must be increased, in which case the isentropic efficiency improves (see isentropic expansion in Figure 4). Otherwise the energy balance is not valid. If the isentropic efficiency improves and the steam flow is not increased, the backpressure in isentropic expansion must be higher than 6 bar to be able to heat the water flow. In Figure 4, the turbine with an isentropic efficiency of 1 represents the best possible turbine which generates no entropy. It is, of course, not possible to have a turbine like this in reality. In general, it is very questionable to use the real environmental temperature for the exergy analysis of the CHP plant because the primary function of the plant is to produce heat and not power.

Figure 5 illustrates a simple industrial process, independent of the ambient temperature, and an industrial CHP plant with a condensing turbine. The left-hand side describes summer and the right-hand 
side winter. The only difference between summer and winter is the temperature of the cooling water used in the condenser. In the summer the temperature of the water is $20{ }^{\circ} \mathrm{C}$ and in the winter $4{ }^{\circ} \mathrm{C}$. The operation and steam use of the industrial process remains unchanged throughout the year. Because of the cooler cooling water in winter, the pressure after the condensing turbine becomes lower and the power production of the turbine increases. Therefore the actual power loss caused by the steam demand of the process is greater in the winter than in the summer, $3,216 \mathrm{~kW}$ and 3,038 $\mathrm{kW}$ respectively.

Figure 5. An industrial process with CHP plant. Summer on the left, winter on the right.
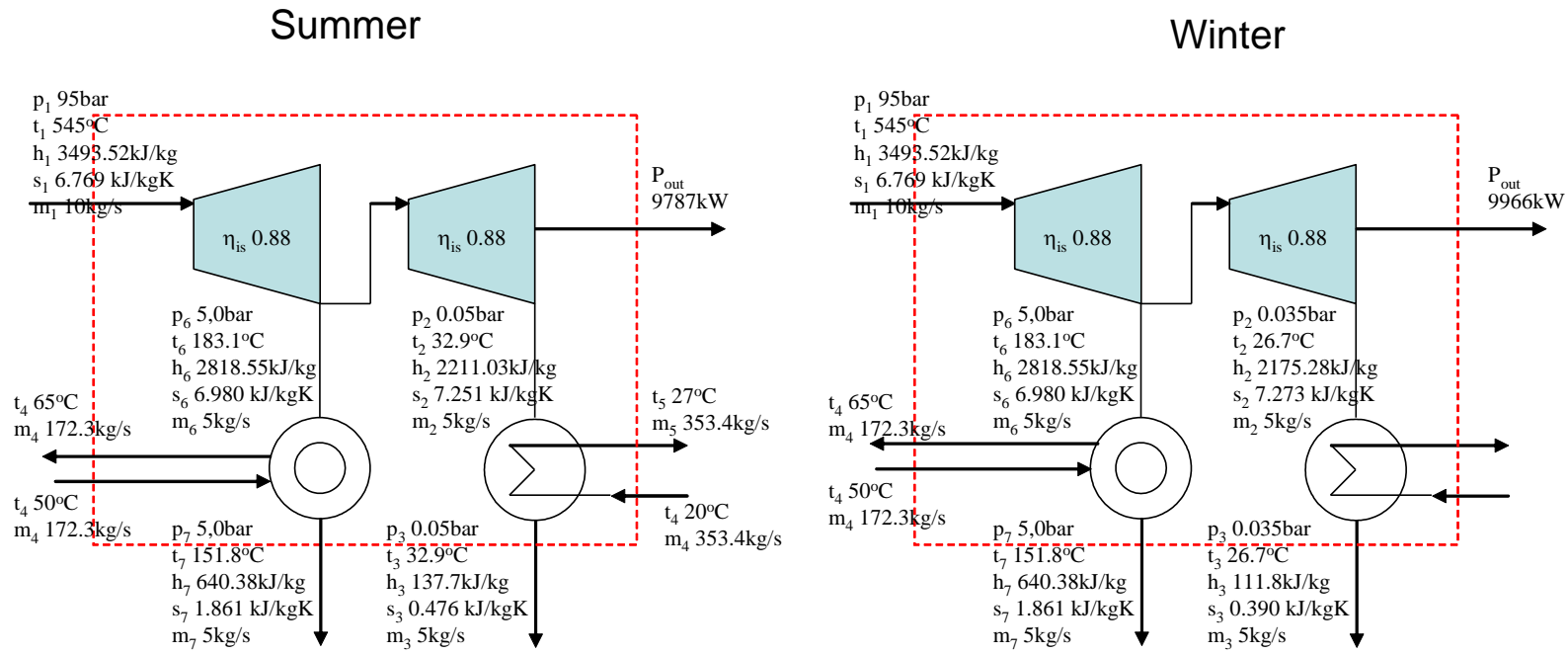

However, if we try to estimate the power loss caused by the industrial process using the Gouy-Stodola law, it gives results that are just the opposite to the example calculation in Figure 5. The entropy generation of the process is the same in the winter and summer. The only change is in the environmental temperature. Therefore the Gouy-Stodola law gives results where the power losses increase when the environmental temperature increases. This is an obvious contradiction compared with the example in Figure 5.

\section{Conclusions}

The power/exergy loss of the system is usually calculated by multiplying the entropy generation rate by the real environmental temperature (the Gouy-Stodola law). The calculated power loss should also be the improvement potential of the system, and the sum of the power loss and real power production should be the maximum power production of the system.

Turbine example calculations (Figure 3) show that it is correct to use the real environmental temperature with the Gouy-Stodola law if the system exchanges heat with the environment only at this temperature. The classic concept of exergy is based on this assumption. However, most industrial processes operate at temperatures higher or lower than the real environmental temperature. In this paper, the maximum power production is achieved when the system is reversible, but it does not have to exchange heat at the real environmental temperature. In these cases, the example calculations show that the sum of the power loss and real power production does not give the correct maximum power production for a reversible system if the real environmental temperature is used with the Gouy-Stodola 
law (Figures 2 and 3). Especially in the case of CHP plant, the errors become significant if the real environmental temperature is used. The paper also shows through turbine examples that the correct power loss can be calculated if the effective temperature defined using Equation (3) is used instead of the real environmental temperature.

In addition, the example calculations reveal that calculation of the effective temperature depends on the system. In the case of adiabatic systems, one must know what flow temperature can be changed to define a reversible system and then the effective temperature (see condensing turbine vs. backpressure turbine).

In this paper, the Gouy-Stodola law has been used by multiplying the entropy generation rate by the effective temperature to calculate the real loss of power caused by the irreversibility of the system. It is obvious that the loss of power is zero if no entropy generation occurs and therefore the design of engineering systems should be based on minimisation of entropy generation, as Bejan states. The minimisation of entropy generation is equivalent to the minimisation of exergy/power losses and is an adequate tool to analyse thermodynamic systems from the viewpoint of the Second Law [7]. In many cases, it is more convenient to calculate the improvement potential in energy units such as Watts or Joules, and therefore the entropy generation rate must be multiplied by an appropriate temperature. The concept of exergy is a useful tool if the theoretical maximum work available from the machine is to be analysed.

\section{Nomenclature}

$c_{p} \quad$ Specific heat capacity $[\mathrm{J} / \mathrm{kgK}]$

E Exergy [W]

h Specific enthalpy $[\mathrm{J} / \mathrm{kg}]$

$\dot{\mathrm{m}}$ Mass flow $[\mathrm{kg} / \mathrm{s}]$

$\mathrm{p}$ Pressure $[\mathrm{Pa}]$

$\mathrm{P} \quad$ Power $[\mathrm{W}]$

Q Heat input/output [W]

$\mathrm{s} \quad$ specific entropy [J/kgK]

$\mathrm{T}$ Temperature [K]

v Specific volume $\left[\mathrm{m}^{3} / \mathrm{kg}\right]$

\section{Greeks}

$\delta \quad$ Entropy generation rate $[\mathrm{W} / \mathrm{K}]$

\section{Subscripts}

$1 /$ in Inlet

2/out Outlet

eff Effective

o Environmental

R Reversible 


\section{References}

1. Szargut, J. The Exergy Method: Technical and Ecological Applications; WIT Press: Ashurst Lodge, Southampton, UK, 2005.

2. Aljundi, H.I. Energy and exergy analysis of a steam power plant in Jordan. Appl. Therm. Eng. 2009, 29, 324-328.

3. Kotas, T.J. The Exergy Method of Thermal Plant Analysis; Malabar: Bethel, CT, USA, 1995.

4. Struchtruo, H.; Rosen, M. How much work is lost in an irreversible turbine. Exergy, An International Journal 2002, 2, 152-158.

5. Szargut, J.; Morris, D.R.; Steward, F.R. Exergy Analysis of Thermal Chemical and Metallurgical Processes; Hemisphere Publishing Corporation: New York, NY, USA, 1998.

6. Wang, J.F.; Dai, Y.P.; Gao, L. Exergy analyses and parametric optimizations for different cogeneration power plants in cement industry. Appl. Energ. 2008, 86, 941-948.

7. Bejan, A. Entropy Generation Minimization; CRC Press: New York, NY, USA, 1996.

8. Lampinen, M.; Wiksten, R. Theory of effective heat-absorbing and heat emitting temperatures in entropy and exergy analysis with applications to flow systems and combustion process. J. Non-Equil. Thermodyn. 2006, 31, 257-291.

9. Lampinen, M.J.; Heikkinen, M.A. Exergy analysis for stationary flow systems with several heat exchange temperatures. Int. J. Energ. Res. 1995, 19, 407-418.

(C) 2009 by the authors; licensee Molecular Diversity Preservation International, Basel, Switzerland. This article is an open-access article distributed under the terms and conditions of the Creative Commons Attribution license (http://creativecommons.org/licenses/by/3.0/). 